
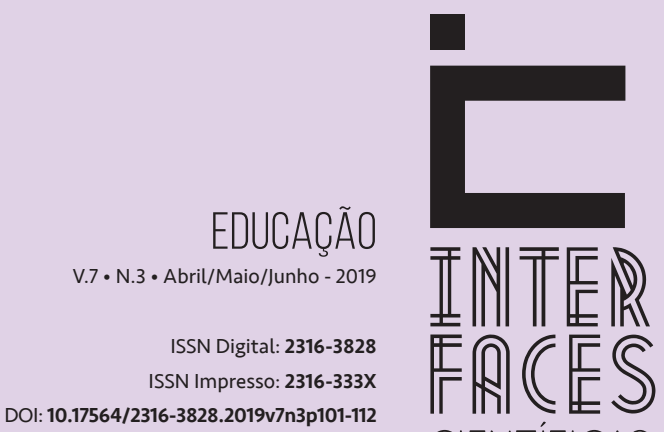

CIENTIIFICAS

\section{LIBRAS NA FORMAÇÃO INICIAL DE PEDAGOGOS: PERCEPÇÕES DOS ESTUDANTES}

LIBRAS IN INITIAL TRAINING OF PEDAGOGUES: STUDENT PERCEPTIONS

LIBRAS EN LA FORMACIÓN INICIAL DE PEDAGOGOS: PERCEPCIONES DE LOS ESTUDIANTES
Josiane Junia Facundo ${ }^{1}$ Célia Regina Vitaliano ${ }^{2}$

\section{RESUMO}

Este artigo propõe analisar os efeitos de algumas das determinações contidas na Lei $n^{0} 10.436$ de 22 de abril de 2002, regulamentada pelo Decreto $n^{\circ}$ 5626 de 22 de dezembro de 2005, no tocante a inserção da disciplina de Língua Brasileira de Sinais (Libras) nos cursos de formação de professores, ministrada por professor preferencialmente surdo. 0 objetivo principal foi discutir os efeitos da disciplina nas primeiras turmas a cursarem tal disciplina como obrigatória em uma das universidades públicas do Estado do Paraná. Em especial, por ter sido a disciplina ministrada por uma professora surda, ressaltaram-se as percepções dos estudantes acerca dessa experiência com a docente, após terem concluído a referida disciplina. Para isso, no estudo de caso, utilizou-se de questionários, para alunos, e de análise documental do programa da disciplina. 0 tratamento dos dados se deu conforme o método de análise de conteúdos sugerido por Bardin (2009), no que se refere à categorização dos dados. Os resultados evidenciaram que a maioria dos estudantes avaliou de forma positiva a inclusão da disciplina como obrigatória no currículo e o fato de ser ministrada por uma professora surda; além de apontarem falhas quanto à carga horária e outros aspectos relacionados às condições de sua oferta.

\section{PALAVRAS-CHAVE}

Libras. Pedagogia. Formação de Professores. 


\section{ABSTRACT}

This article proposes to analyze the effects of some of the determinations contained in Law 10.436 of April 22, 2002, regulated by Decree 5626 of December 22, 2005, regarding the insertion of the discipline of Brazilian Sign Language (Libras) in training courses of teachers, taught by a rather deaf teacher. The main objective was to discuss the effects of the discipline in the first classes to attend such a course as mandatory in one of the public universities of the State of Paraná. In particular, because it was the discipline taught by a deaf teacher, the students' perceptions about this experience with the teacher were emphasized after completing the subject. For this, the case study was used of questionnaires, for students, and of documentary analysis of the program of the discipline. The data treatment was carried out according to the content analysis method suggested by Bardin (2009), regarding the categorization of the data. The results showed that the majority of the students evaluated in a positive way the inclusion of the subject as compulsory in the curriculum and also the fact that it was given by a deaf teacher; besides pointing out failures regarding the workload and other aspects related to the conditions of their offer.

\section{KEYWORDS}

Libras. Pedagogy. Teacher Training.

\section{RESUMEN}

Este artículo propone analizar los efectos de algunas de las determinaciones contenidas en la Ley 10.436 de 22 de abril de 2002, regulada por el Decreto 5626 de 22 de diciembre de 2005, en lo que se refiere a la inserción de la disciplina de Lengua Brasileña de Señales (Libras) en los cursos de formación de profesores, impartida por profesor preferentemente sordo. El objetivo principal fue discutir los efectos de la disciplina en las primeras clases a cursar tal disciplina como obligatoria en una de las universidades públicas del Estado de Paraná. En especial, por haber sido la disciplina impartida por una profesora sorda, se resaltaron las percepciones de los estudiantes acerca de esa experiencia con la docente, después de haber concluido la referida disciplina. Para eso el estudio de caso se utilizó de cuestionarios, para alumnos, y de análisis documental del programa de la disciplina. El tratamiento de los datos ha sido realizado según el método de análisis de contenidos sugerido por Bardin (2009), en lo que se refiere a la categorización de los datos. Los resultados evidenciaron que la mayoría de los estudiantes evaluaron de forma positiva la inclusión de la disciplina como obligatoria en el currículo y también el hecho de ser ministrada por una profesora sorda; además de apuntar fallas acerca a la carga horaria y otros aspectos relacionados a las condiciones de su oferta. 


\section{PALABRAS CLAVE}

Libras; Pedagogía; Formación de profesores.

\section{INTRODUCÇÃO}

O Decreto no 5.626/05, publicado em 2005 constitui-se no documento mais significativo, até o momento, no que se refere à educação das pessoas surdas no Brasil, visto que por meio dele a Língua Brasileira de Sinais, denominada Libras, já reconhecida há 15 anos, foi regulamentada. Destaca-se, também nesse decreto e na lei de reconhecimento da Libras (lei n 10.436/02) a determinação da inclusão da Libras como disciplina curricular obrigatória nos cursos de formação de professores e de fonoaudiologia, nos seguintes termos:

Art. 30 A Libras deve ser inserida como disciplina curricular obrigatória nos cursos de formação de professores para o exercício do magistério, em nível médio e superior, e nos cursos de Fonoaudiologia, de instituições de ensino, públicas e privadas, do sistema federal de ensino e dos sistemas de ensino dos Estados, do Distrito Federal e dos Municípios.

$\S 10$ Todos os cursos de licenciatura, nas diferentes áreas do conhecimento, o curso normal de nível médio, o curso normal superior, o curso de Pedagogia e o curso de Educação Especial são considerados cursos de formação de professores e profissionais da educação para o exercício do magistério (BRASIL, 2005).

Ao direcionar a disciplina aos cursos de formação de professores (exceto o de fonoaudiologia); o decreto direciona para a preparação dos futuros professores que poderão receber alunos surdos em suas salas de aula, em consonância com as demais legislações educacionais do país referentes à inclusão de alunos com Necessidades Educacionais Especiais (NEE).

A partir dessas considerações, buscamos verificar o efeito da disciplina de Libras na formação de estudantes de Pedagogia de uma Instituição de Ensino Superior (IES) do interior do Estado do Paraná, sob o ponto de vista desses participantes; destacando suas experiências com uma professora surda e suas percepções acerca da disciplina, nos aspectos curriculares.

Os dados foram analisados de acordo com as orientações de Bardin (2009) para análise de conteúdos; no que se refere à categorização dos dados.

A fundamentação teórica é tecida nos moldes da literatura referente à educação inclusiva, compreendendo a legislação a ela relacionada. 


\section{FUNDAMENTAÇÃO TEÓRICA}

O processo de formação de professores não pode mais ignorar as diferentes condições de aprendizagem dos alunos que passaram a integrar o sistema de ensino, a partir da adoção de políticas educacionais inclusivas, visto que a escola assume o compromisso de oferecer a todos os alunos, incluindo aqueles que apresentam NEE, uma educação de qualidade.

Sabemos, no entanto, que de fato a realidade encontrada na maioria das escolas brasileiras está bem aquém de oferecer a qualidade almejada e atender às determinações dispostas nas políticas referentes à educação de alunos com NEE.

Em relação à educação das pessoas surdas, Carvalho e Tavares (2010, p. 3-4) assinalam que:

Percebe-se que em nosso país, entre os documentos que compõem o conjunto de leis denominado Políticas Públicas e sua implementação, há um grande fosso. Com as políticas públicas educacionais na área de educação de surdos, não é diferente. Há lei para acessibilidade que garante intérprete de Língua de Sinais/Língua Portuguesa durante as aulas, flexibilidade na correção das provas escritas, materiais de informação aos professores sobre as especificidades do aluno surdo etc. Mas, na prática, o que se percebe, é o aluno surdo mais excluído do que incluído nas salas de aula regulares, enfrentando dificuldades, que, muitas vezes os seus familiares é que tentam minimizar, buscando soluções nem sempre eficientes para ajudá-los. Por outro lado, professores, em sua maioria, sem conhecimento mínimo da Libras e, algumas vezes, subsumido por uma carga horária de trabalho exaustiva, não têm tempo para buscar uma formação continuada na área.

As barreiras comunicativas, bem como o desconhecimento das NEE dessa população na escola, acabam gerando dificuldades e equívocos relacionados ao seu atendimento educacional. Machado (2008) observa que devido à tradição oralista e as ideias disseminadas por essa abordagem ao longo de um período considerável na história da educação de surdos, muitos professores, quando recebem um aluno surdo em sala de aula, colocam-no à frente dos demais, na primeira carteira e procuram falar de frente para esse aluno, supondo que ele fará leitura labial e conseguirá acompanhar as aulas como os demais alunos.

Um dos motivos desses comportamentos diante do aluno surdo deve-se à formação do professor, pois como salienta Gesser (2009, p. 292),

A maioria dos cursos universitários que preparam os profissionais para atuar com a surdez têm insistentemente localizado tais indivíduos na narrativa da deficiência, promovendo concepções geralmente simplificadas, construídas a partir de traços negativos como, por exemplo, a falta de língua(gem).

Com a introdução da Libras como disciplina curricular nas licenciaturas, por meio da determinação do Decreto 5626/05, estima-se que a surdez tenderá a ser dissociada, gradativamente, da pers- 
pectiva da deficiência, o que refletirá de modo expressivo, no processo de inclusão dos surdos no ensino regular, pois como assinala Machado (2008, p. 78), "pouco adianta a presença de surdos se a escola ignora sua construção histórica, cultural e social”.

Alguns aspectos, todavia, devem ser considerados quando se trata da introdução da disciplina de Libras no currículo dos cursos de formação de professores, tais como: a carga horária, a natureza, teórica ou prática, o conteúdo proposto, por exemplo, vemos em diversas ementas disponíveis na internet discussões voltadas para a deficiência auditiva em detrimento do conhecimento cultural, linguístico e pedagógico para a atuação com alunos surdos. Portanto, podemos considerar que a forma como se organiza a referida disciplina pode influenciar amplamente o seu efeito no processo de formação dos professores (VITALIANO et al., 2013).

Mas, independentemente de tais aspectos, o fato de termos a disciplina de Libras como obrigatória na formação de professores já pode ser considerado um grande avanço. Strobel (2008, p. 102) considera que:

São raros os professores habilitados para trabalhar com os alunos surdos em sala de aula. Na maioria dos cursos de Pedagogia nas universidades não tinham estas especializações para esta área - somente agora salvo pelo decreto n. 5626, de 22 de dezembro de 2005 que dá obrigatoriedade das aberturas de cursos de Libras nestes cursos, as coisas podem melhorar.

Entre as muitas funções que são atribuídas ao professor, acrescenta-se o domínio da Libras para atuar com alunos surdos. Todavia esta é uma habilidade que nem todos conseguem desenvolver em apenas uma disciplina semestral. 0 fato de a disciplina de Língua Brasileira de Sinais (LIBRAS) ser obrigatória nos cursos de formação de professores pode ter dado a entender que o professor regente deverá ministrar suas aulas em Libras, o que seria tecnicamente impossível (BOTELHO, 2007). Além do mais, apropriar-se efetivamente da Língua de Sinais, assim como de qualquer outra língua, requer muito mais que um semestre ou um ano todo de curso.

O conhecimento da Libras, no entanto, quanto à sua estrutura lexical, sintática esemântica, seria fundamental ao professor, sobretudo para compreender a importância de buscar formas de explicar o conteúdo de modo mais claro e sucinto, facilitando o trabalho do tradutor-intérprete, bem como possibilitar uma melhor interação entre professor e aluno. Como assinala Reily (2008, p. 125),

[...] mesmo na escola que conta com um intérprete, com uma sala de recursos, com serviço e apoio de professor de educação especial ou professor itinerante, é de fundamental importância que o aluno sinta que seu professor está se esforçando para se aproximar dele, tentando encontrar maneiras de interagir com ele. 0 professor também pode intermediar a aceitação do aluno pelos outros alunos, para que ele se sinta parte da classe. Na nossa sociedade, a interação se dá mediada pela linguagem. Não basta uma aproximação física.

O Decreto 5626/05, em seu Capítulo IV, art. 14, também enfatiza a necessidade de o professor conhecer a forma de comunicação dos alunos surdos ao trazer como meta a formação do "professor 
regente de classe com conhecimento acerca da singularidade linguística manifestada pelos alunos surdos". Talvez esse item seja o que melhor justifica a disciplina de Libras na formação de professores e que deveria nortear os planejamentos da disciplina, principalmente a seleção de conteúdos que serão ministrados, cuidando desse modo para que ela não se equipare a um curso básico de Libras.

Conhecer a singularidade linguística manifestada pelos alunos surdos é um dos principais objetivos de se inserir a Libras no currículo das licenciaturas. Devemos levar em conta, que os alunos com surdez precisam de ambientes educacionais estimuladores, que desafiem o pensamento e explorem suas capacidades cognitivas por meio de um ensino bilíngue.

Desse modo, consideramos que, investir na formação de professores, tanto em formação inicial como formação continuada, é a melhor forma de contribuir com o processo educacional inclusivo de surdos, visto que, quase todos os fatores que interferem para que o processo de inclusão seja efetivo estão relacionados às atitudes e práticas cotidianas em sala de aula; seja referente à didática do professor ou às relações sociais dele para com os alunos ou as que ele pode mediar entre eles.

Conquanto, algumas questões precisam ser levantadas e discutidas para que o processo de implementação da Libras nas licenciaturas tenha maior êxito, entre as quais podemos elencar a receptividade dessa disciplina pelos participantes, o modo como se tem dado o ensino dela, quais conteúdos são contemplados, qual o perfil do profissional que a ministra, entre outras. Consideramos que algumas dessas questões nortearam o presente artigo que tem como objetivos: identificar junto aos alunos de um curso de Pedagogia, de uma IES pública, suas percepções acerca da obrigatoriedade da disciplina; suas experiências com a professora surda; as possíveis dificuldades que sentiram durante a realização da disciplina; avaliações sobre os conteúdos mais relevantes da disciplina e os saberes considerados necessários ao professor para inclusão dos alunos surdos.

A seguir são apresentados os caminhos trilhados para atingir tais objetivos.

\section{MÉTODO}

Esta pesquisa, de natureza exploratória, constitui-se em um estudo de caso. Foi realizada por meio da aplicação de um questionário junto aos graduandos do curso de Pedagogia de uma IES pública brasileira, situada na região norte do Estado do Paraná, no ano de 2010. Esses graduandos se encontravam em fase de finalização do curso e estavam, também, concluindo a disciplina de Libras, disposta na grade curricular no último semestre do curso. Ao todo foram analisados 40 questionários.

Os 40 alunos participantes apresentavam as seguintes características: $5 \%$ eram do sexo masculino, sendo os outros $95 \%$ constituídos por pessoas do sexo feminino. A faixa etária dos alunos participantes variou entre 21 e 47 anos. Vale destacar que 7,5\% não preencheram o espaço no questionário referente ao item “idade”. Dos alunos participantes, $60 \%$ afirmaram que ainda não atuavam no magistério. Os demais $40 \%$ dos alunos participantes afirmaram que já tinham algum tempo de atuação no magistério. Dos alunos que possuíam experiência na docência, $69 \%$ atuavam há menos de cinco anos na área, enquanto os outros $31 \%$ já atuavam há mais de cinco anos. 
As questões contidas nos questionários que foram alvos de análise do presente artigo versaram sobre os seguintes temas: concepções acerca da Libras como disciplina obrigatória da matriz curricular; considerações acerca do profissional que deve ministrar a disciplina, se surdo ou ouvinte; dificuldades encontradas pelos participantes ao cursar a disciplina de Libras; e as percepções dos alunos acerca dos conteúdos da disciplina de Libras.

Destacamos que essas turmas foram as primeiras do curso de Pedagogia da IES analisada que tiveram a disciplina de Libras como obrigatória em sua matriz curricular.

Realizou-se, também, considerando que esta pesquisa analisa as opiniões dos participantes a respeito da disciplina de Libras, uma análise documental de sua ementa, visto que seus conteúdos foram foco de algumas das análises realizadas.

\section{RESULTADOS E DISCUSSÃO}

Os resultados serão apresentados divididos em categorias de acordo com as orientações de Bardin (2009), referente à análise de conteúdo.

\subsection{OBRIGATORIEDADE DA DISCIPLINA DE LIBRAS NO CURRÍCULO DE PEDAGOGIA}

Com o intuito de analisar a receptividade da disciplina no curso pesquisado, questionamos os alunos sobre suas posições pessoais em relação à inclusão da disciplina de Libras em seu curso, tendo em vista que essa disciplina foi imposta por lei como obrigatória.

De acordo com os dados dos questionários, verificamos que $97,5 \%$ dos alunos participantes concordavam com a obrigatoriedade da Libras em seu curso, enquanto apenas 2,5\% discordavam dessa determinação.

\subsection{0 “PREFERENCIALMENTE SURDO” CONTIDO NO DECRETO 5626/05 E A EXPERIÊNCIA DOS ESTUDANTES}

Ao se levar em conta que as turmas analisadas tiveram uma professora surda e que o Decreto 5626/05 prioriza a atuação de docente surdo para ministrar a disciplina de Libras nas universidades brasileiras, buscou-se identificar como se deu a aceitação desse profissional no contexto acadêmico.

Ao serem questionados sobre sua preferência em relação ao professor da disciplina de Libras ser surdo ou ouvinte, os participantes apresentaram os seguintes resultados: $45 \%$ consideraram que a disciplina poderia ser ministrada tanto por surdos quanto por ouvintes, 42,5\% manifestaram preferência por professores surdos e $5 \%$ por professores ouvintes. Houve também 2,5\%, que não se manifestaram, ou seja, não responderam essa questão.

Os alunos que se manifestaram indiferentes, quanto ao professor ser surdo ou ouvinte, destacaram que independente da condição auditiva do professor, o importante seria a competência profissional relacionada ao domínio de conteúdo ou conhecimento didático/metodológico; a importância da comunicação e a de se conhecer a realidade dos surdos. 
A parcela significativa de alunos que manifestou preferência por professor surdo considerou a experiência ou vivência do professor. Essa justificativa aparece também nas análises de Rebouças (2009) entre os alunos que têm preferência por professores surdos. Alguns, ainda, enfatizaram a cultura e o conhecimento do professor surdo sobre a Libras.

Uma das principais reivindicações das pessoas surdas, profissionais da educação, tem sido a de terem prioridade no ensino da língua de sinais. Essa luta por maior oportunidade de trabalho, no que se refere ao ensino de Língua de Sinais, vem acontecendo há alguns anos no Brasil; juntamente com a luta pelo reconhecimento da própria língua brasileira de sinais, evidenciando-se no discurso de líderes surdos, em congressos, seminários, encontros e outros eventos relacionados, principalmente, à educação de surdos, além de documentos que manifestam essa reivindicação.

\subsection{DIFICULDADES ENCONTRADAS PELOS PARTICIPANTES AO CURSAR A DISCIPLINA DE LIBRAS}

Interessou-nos detectar, tendo em vista o objetivo de acompanhar o processo de implementação da disciplina de Libras, as principais dificuldades que os alunos identificaram quando a vivenciarem. Identificamos que mais da metade dos participantes (52,5\%) respondeu que não teve dificuldades. No entanto, uma parcela considerável dos alunos (45\%) afirmou ter encontrado dificuldades e os demais alunos (2,5\%) não se manifestaram.

Identificamos que, considerando o percentual de alunos participantes, que apresentaram dificuldades, $17,5 \%$ das dificuldades estavam relacionadas à complexidade dos conteúdos, $15 \%$ à coordenação motora ou memorização; 10\% justificaram a dificuldade de aprendizagem, devido à carga horária da disciplina; e 2,5\% apontaram dificuldades de comunicação com a professora, esta última justificada pela falta de intérpretes.

Vale ressaltar que, alguns alunos, apesar de terem afirmado não encontrarem dificuldades na disciplina, comentaram algumas, como podemos observar no relato a seguir: "Não. Mas os colegas sim, pois a apostila utilizada não dava conta de me apoiar nos conteúdos ministrados em sala" (aluno de Pedagogia). Neste relato verificamos que o aluno deixa explícito que não conseguia acompanhar o conteúdo, mesmo tendo a apostila como apoio.

A maioria dos alunos que respondeu que não apresentou dificuldades na disciplina também não apresentou justificativa de sua resposta, tendo em vista que a questão não exigia justificativa.

Quadros e Campello (2010) ressaltam que a proposta da disciplina de Libras no Curso de Pedagogia é de oferecer conhecimentos básicos dessa Língua. Depreendemos que o nível de aquisição da língua de sinais esperado e trabalhado na disciplina de Libras do curso analisado tenha sido o básico, tendo em vista o tempo da disciplina e os conteúdos teóricos abordados. Este, provavelmente tenha sido o motivo pelo qual $52,5 \%$ dos participantes relataram não ter encontrado dificuldades, pois a aprendizagem de qualquer língua é complexa. Pensar que a língua de sinais seria diferente é banalizá-la. Além do mais não se pode ignorar que boa parcela dos alunos, em relação aos conhecimentos básicos da língua de sinais, admitiu encontrar dificuldades.

Quanto à aprendizagem da Língua de Sinais, além das questões estruturais ou gramaticais, comuns à aprendizagem de outras línguas, são necessárias habilidades motoras e expressivas, o que dificulta ainda mais a aprendizagem dessa língua. 


\subsection{PERCEPÇÕES DOS PARTICIPANTES ACERCA DOS CONTEÚDOS DA DISCIPLINA DE LIBRAS}

Outro aspecto que motivou a presente pesquisa foi o fato de o Decreto 5626/05 não apresentar de modo claro os objetivos ao propor a obrigatoriedade da disciplina de Libras nos cursos de formação de professores; bem como a verificação de que as universidades brasileiras têm organizado a ementa da referida disciplina com diferentes enfoques.

Com o intuito de sondar as expectativas dos alunos acerca dos conteúdos da disciplina de Libras, solicitamos a opinião deles sobre quais conteúdos consideravam mais relevantes para a referida disciplina. Identificamos que $20 \%$ desses participantes referiram-se a conteúdos práticos, que envolviam a realização dos sinais, outros $20 \%$ consideraram relevantes, tanto os conteúdos práticos como os teóricos, $15 \%$ referiram-se a conteúdos teóricos e os demais 15\% fizeram outras considerações.

Com relação aos conteúdos que os alunos participantes consideravam mais relevantes na disciplina de Libras, encontramos em $25 \%$ das respostas referências a conteúdos práticos, envolvendo a aprendizagem da língua de sinais, em 7,5\% ao estudo da história e cultura dos surdos, em $5 \%$ à Metodologia/ estratégias de ensino, outros 5\% à Avaliação, 5\% à Didática, 5\% ao Atendimento de alunos surdos em sala de aula e 2,5\% à Adaptação curricular.

De acordo com o que pudemos observar, a aprendizagem da língua de sinais fez parte da expectativa de grande parte dos alunos. É compreensível que eles esperem por aulas práticas de Libras, visto que o nome da disciplina é bastante sugestivo nesse sentido.

Contudo os alunos também reconheceram a necessidade de aprender conteúdos teóricos que possam contribuir para sua atuação com alunos surdos, ou seja, relacionados ao processo de ensino-aprendizagem.

Haveria então, se fossem atendidas as expectativas dos alunos em relação aos conteúdos da disciplina, um equilíbrio entre os saberes voltados às orientações sobre práticas pedagógicas adequadas para se atender alunos surdos em contextos escolares inclusivos e conhecimentos específicos da língua de sinais.

Ao questionarmos os alunos se suas expectativas foram atendidas em relação à disciplina de Libras, foi possível identificar expectativas relacionadas aos conteúdos práticos da língua e outros relacionados ao contato com a professora surda, sendo essa experiência avaliada como positiva.

No entanto, alguns enfatizaram a carga horária da disciplina como insuficiente para o desenvolvimento do conteúdo proposto, apesar de terem respondido que os conteúdos contemplaram suas expectativas iniciais. Não podemos negar que o tempo da disciplina é insuficiente para adquirir fluência em Libras.

A pesquisa de Pereira (2008), acerca da implementação da disciplina de Libras no Ensino Superior, demonstra, a partir do relato de coordenadores de alguns cursos de Pedagogia, que a única disciplina que aborda a temática da educação de surdos nos referidos cursos é a Libras.

Desse modo, é inegável o papel da disciplina de formar professores regentes que conheçam a surdez e suas especificidades, bem como questões linguísticas, culturais, cognitivas e pedagógicas, dado a importância de, como afirmam Carvalho e Tavares (2010, p. 8), "professores com formação adequada para o trabalho pedagógico, o qual possui como condição básica, a comunicação”.

Cabe aos docentes de Libras e coordenadores dos cursos, tendo em vista que o aumento da carga horária da disciplina impacta consideravelmente a grade curricular, a organização dos conteúdos relevantes que contemplem a aprendizagem da língua e questões educacionais sobre o aluno surdo. 


\subsection{SABERES NECESSÁRIOS AO PROFESSOR SOB A ÓTICA DA EDUCAÇÃO INCLUSIVA}

O Artigo 22 do Decreto 5626/05 estabelece que “as instituições federais de ensino responsáveis pela educação básica devem garantir a inclusão de alunos surdos ou com deficiência auditiva, por meio da organização de escolas e classes de educação bilíngue”. Considerando a futura atuação dos participantes de Pedagogia no contexto da educação inclusiva, buscamos verificar quais os saberes que os participantes consideravam necessários para atuar junto a alunos surdos nas classes comuns do ensino regular.

O conhecimento da língua de sinais foi o mais indicado como habilidade necessária para o trabaIho educativo com alunos surdos, aparecendo em $27,5 \%$ das respostas. Esse percentual se refere às respostas que colocam apenas esse conhecimento linguístico como necessário.

Porém, 22,5\% dos participantes destacaram saberes relacionados tanto à Libras como à educação ou inclusão de alunos surdos, enquanto $17,5 \%$ consideram necessários alguns saberes relacionados às condições pedagógicas para a inclusão desses alunos. Outros $17,5 \%$ dos participantes ressaltaram a importância de uma especialização na área para aprofundar os conhecimentos relacionados ao trabalho com alunos surdos.

Pudemos perceber também que alguns participantes citaram o auxílio de intérpretes ou mesmo de um auxiliar em sala para favorecer a inclusão do aluno surdo. Ainda houve, em 7,5\% das respostas dos alunos, referência à cultura surda, ou algo relacionado, como a expressão "mundo dos surdos", o que denota uma visão mais cultural da surdez em detrimento da visão clínica ou patológica:

De modo geral observamos que a maioria dos participantes, com maior ou menor ênfase conseguiu perceber que o trabalho com alunos surdos requer outros saberes, além do domínio da língua, especialmente aqueles relacionados a aspectos pedagógicos.

\section{CONSIDERAÇÕES FINAIS}

Consideramos que os dados coletados por meio do questionário foram produtivos, tendo em vista os objetivos iniciais. Contudo, sabemos que as reais contribuições da disciplina se manifestarão na prática, quando o professor vivenciar o atendimento a alunos surdos em sua sala de aula.

Em relação às principais dificuldades encontradas no decorrer da disciplina, como vimos, os participantes identificaram o desenvolvimento das habilidades específicas para a prática da língua de sinais, a carga horária da disciplina, a falta de um intérprete como apoio durante as aulas, entre outras.

Entre os aspectos que favoreceram o processo de implementação da disciplina destacamos a oportunidade que os participantes tiveram de contato com a professora surda, o qual proporcionou maior conhecimento da cultura dos surdos e possibilitou a prática da língua de sinais a qualquer momento da aula, a boa receptividade à disciplina, os conteúdos considerados relevantes que demonstraram uma preocupação voltada à prática pedagógica com alunos surdos, bem como demonstraram por meio da indicação dos saberes necessários a essa atuação. 
Consideramos que este estudo ofereceu pistas sobre aspectos relevantes a serem observados na implementação da disciplina em foco nos cursos de formação de professores, podendo assim contribuir para o aprimoramento do processo.

\section{REFERÊNCIAS}

BARDIN, L. Análise de conteúdo. Lisboa: Editora Geográfica, 2009.

BOTELHO, P. Linguagem e letramento na educação dos surdos. Belo Horizonte: Autêntica, 1998.

BRASIL. Decreto n 5.626, de 22 de dezembro de 2005. Regulamenta a Lei no 10.436, de 24 de abril de 2002, que dispõe sobre a Língua Brasileira de Sinais - Libras, e o art. 18 da Lei no 10.098, de 19 de dezembro de 2000. Diário Oficial da União, Brasília, DF, dezembro de 2005. Disponível em: http:// www.planalto.gov.br/ccivil_03/_ato2004-2006/2005/decreto/d5626.htm. Acesso em: 30 mar. 2015.

CARVALHO, T. S. S.; TAVARES, I. M. S. Inclusão escolar e a formação de professores para o ensino de Libras (Língua Brasileira de Sinais): do texto oficial ao contexto. In: Pesquisa em Educação: Desenvolvimento, ética e responsabilidade social, 2010. Maceió. V EPEAL.

GESSER, A. Do patológico ao cultural na surdez: para além de um e de outro ou para uma reflexão crítica dos paradigmas. In: QUADROS, R.M de; STUMPF, M. R. Estudos Surdos IV. Petrópolis: Arara Azul, 2009.

MACHADO, P. C. A política educacional de integração/inclusão: um olhar do egresso surdo. Florianópolis: Editora da UFSC, 2008.

QUADROS, R.; CAMPELLO, A.R.S. A constituição política, social e cultural da língua brasileira de sinais- Libras. In: VIEIRA-MACHADO, L. M.C.; LOPES, M. C. Educação de surdos: políticas, línguas de sinais, comunidade e cultura surda. Porto Alegre: Artes Médicas, 2010.

REBOUÇAS. L. S. A prioridade dos docentes surdos para ensinar a disciplina Língua Brasileira de Sinais (Libras) nas instituições de ensino superior após o Decreto 5.626/2005. 2009. $171 \mathrm{fl}$. Dissertação (Mestrado em Educação) - Universidade Federal da Bahia, Salvador, 2009.

REILY, L. Escola inclusiva: linguagem e mediação. Campinas: Papirus Editora, 2008.

STROBEL, K. L. As imagens do outro sobre a cultura surda. Florianopólis: Editora da UFSC, 2007. 
VITALIANO, C. R.; DALL' ACQUA, M. J. C.; BROCHADO, S. M. D. A disciplina Língua Brasileira de Sinais nos currículos dos cursos de Pedagogia.

Boletim Técnico do SENAC, v. 39, n. 2, p. 106-121, maio/ago. 2013. Disponível em: http://www.senac. br/media/42510/os_boletim_web_7.pdf.

Acesso em: 30 mar. 2014
Recebido em: 19 de Outubro de 2017

Avaliado em: 17 de Maio de 2018

Aceito em: 17 de Maio de 2018

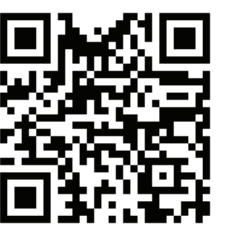

A autenticidade desse artigo pode ser conferida no site https://periodicos. set.edu.br

\section{Como citar este artigo:}

FACUNDO, Josiane Junia; VITALIANO,

Célia Regina. Libras na formação inicial de pedagogos: percepções dos estudantes. Interfaces Científicas - Educação, Aracaju- SE-

BRASIL, v. 7, n. 3, 2019, p.101-112. DOI: 0000000

\section{(c) (1) (2)}

Este artigo é licenciado na modalidade acesso abertosob a Atribuição-Compartilhalgual CC BY-SA

1 Professora do Instituto Federal de Educação do Tocantins - IFTO; Doutoranda do Programa de Pós-graduação em Estudos da Linguagem da Universidade Estadual de Londrina- UEL. E-mail: josiane.almeida@yahoo.com.br

2 Professora Doutora Associada do Departamento de Educação da Universidade Estadual de Londrina.

E-mail: reginavitaliano@gmail.com 